\title{
Polish and Swedish journalist-politician Twitter networks: Who are the gatekeepers?
}

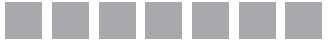 \\ Elena Johansson \\ ORCID: 0000-0002-5786-1106 \\ UMEA UNIVERSITY, SWEDEN \\ Jacek Nożewski \\ ORCID: 0000-0001-7211-147X \\ UNIVERSITY OF WROCŁAW, POLAND
}

DOI: 10.19195/1899-5101.11.2(21).2

\begin{abstract}
The relationship between journalists and political sources takes different forms and extends from adversarial to advocating. The question which side 'leads the tango' has always been central to this approach. Since technological development has led to hybridization of (the)media system(s), the nature of communication has been reshaped in many ways. The emergence of social media has challenged the journalistic profession, especially journalists' role as gatekeepers, but provided extra space for interaction with sources. Increasing professionalization of politics has reinforced the role of press secretaries/advisers. This is a comparative study of interaction among Polish and Swedish journalists, ministers, and press secretaries in Twitter provided by network analysis and three social network concepts as density, modularity, and centralization. In this analysis, a more influential position is conceptualized in terms of 'communicative resources' or 'accumulated capacity'. Swedish journalists have more opportunities to act as gatekeepers (or 'key users') in the Twitter network; in Poland, it is rather the political side.
\end{abstract}

KEYWORDS: political/government communication, journalists, ministers, press secretaries, relations, gatekeepers, network analysis, Twitter.

\section{MEDIA-POLITICS RELATIONS: A BACKGROUND}

This article proposes an approach to studying journalist-(political) source relations in social media networks in a comparative perspective presented by the cases of Poland and Sweden. On the ground of journalist-source relations lies different factors; they are usually rooted in the specificities of media-political systems. Following the classical Hallin and Mancini's (2004) concept, political communication 
culture depends on the local politico-economic context which can also impact journalism culture as well as relations between media and politicians.

In this meaning, Sweden and Poland are completely different. Sweden belongs to the North/Central European or Democratic Corporatist Model. It is based on a coexistence of three elements: political parallelism, a high level of journalistic professionalization, and strong state intervention with protection of press freedom (Hallin \& Mancini, 2004, p. 143). Thus, Swedish journalists have always played a watchdog role in society. They have traditionally had a responsibility to scrutinize the political system and to criticize political and social elites.

Analyzing journalist-source relations from a social constructionist perspective, Falkheimer (2005, p. 295) concludes that relations between political/economic elites and the regional Danish and Swedish media have rather a symbiotic nature. Johansson et al. (2018, forthcoming) specify that journalist-source relations in Sweden, traditionally rooted in the old system of party press, developed to a system based on professionalization of both parties. They take a form of "professional symbiosis": close but without friendship or a mixture of private and professional.

Poland, being "beyond the Western world", does not fit into classical models of media and politics conceptualized by Hallin and Mancini (2004). Dobek-Ostrowska (2012, p. 26) places the Polish model between Polarized Pluralist (the Mediterranean) and Liberal (the North Atlantic) models. Polish journalists have usually followed an advocacy style in relations with political sources (Dobek-Ostrowska, 2012, p. 36). However, they have historically specific attitudes: to be "against the official authorities" (Dobek-Ostrowska, 2015, p. 205).

In the case of Poland, the media tends to be characterized as practicing a consumerist approach toward their audiences while at the same time favoring the hidden agendas of politicians" (Balčytienè \& Moring, 2018, forthcoming).

The media sector in Poland is quite commercialized with a significant share of foreign ownership, a high level of state intervention in public service broadcasting and its affiliation with the government and ruling party (Dobek-Ostrowska, 2012, p. 41; Głowacki, 2008, p. 112). Journalistic professionalism is relatively low, with clear elements of media partisanship.

Berkowitz (2009, p. 107) points out, that shaping of journalist-source relationships are mostly grounded on the key principles of journalism's professional ideology. However, the professional ideology can also take different forms in the different media systems. Traditionally in the East (Asia), journalists being more loyal toward power provide a function of 'social moderators', while in Western countries they rather act as 'watchdogs' following principles of detachment and impartiality. Cultural factors play significant but not, however a crucial role.

Theoretically these relations lie between two polar dimensions: adversativity is based on critical scrutinizing over political elites while advocacy adopts non-objective viewpoints in favor of social or political groups. In the symbiotic relations both parties gain a mutual benefit giving something to each other. Practically, the 
journalist-source relationships always depend on different factors as, for example, gender, ethnicity, technology and so on. Thus, the relationship is constantly under negotiation and usually have both adversarial and symbiotic elements (Berkowitz, 2009, p. 111).

In the course of the last decade, however, media systems undergone multiple changes. Among other things these caused the trend of convergence of media systems toward the Liberal Model. It is embodied in the increasing role of commercial media; in the adoption of professional conventions (informational, politically non-aligned, dramatized); and in the shifts toward more personalized, marketing-oriented forms of political communication (Hallin \& Mancini, 2017, p. 162). On the other hand, professionalization of political communication became also an influential trend.

The effect of the rapidly developed Internet-based media and related tendencies was not considered in the Three Models of Media and Politics. Since the media world became digital, the rapid diffusion of new technologies has caused a reshaping of the media system. New media forms and channels of communication arose, and their popularity increased. In this relation, Chadwick (2013) suggests the concept of a hybrid media system, implying that new (or better to say newer) and old (older) media forms interact, compete and mingle with each other, resulting in a process of simultaneous integration and fragmentation. The nature of communication, e.g., political, has also undergone changes.

The level of political parallelism has significantly decreased in European countries.

Another challenge is the political shift toward populism and illiberalism in Europe. After the last election in Poland in 2015, a right-wing national conservative party returned to power. It has caused a strong polarization in the Polish media system, dismissals of disloyal journalists and increasing supervision over public media. Public TV has become a tool for government propaganda while the largest commercial media have become the proponents of their political opponents - the liberal political party in Poland.

Balčytiene and Moring (2018, forthcoming) consider the differences in the mediapolitics relationship through the perspective of the political communication culture. It includes "historical differences in state formation and consequent homogeneity of its geopolitical position and its demography; structural differences based on legislation, regulations and institutional practices; professionalization of politicians and journalists; the size of the country in terms of geographical and social/professional proximity; and also in new trends in media and political currents that are fundamentally transforming the contemporary political landscape in today's Europe".

The authors suggest the original approach shows quite fundamental varieties of government institutional vs. media professional logics' combinations (Figure 1).

Thus, Poland, being a former 'semi-communist' state, has a long tradition of a political culture based on clientelism and personalized relations. Political parallelism takes a form of instrumentalization of (public service) media while govern- 


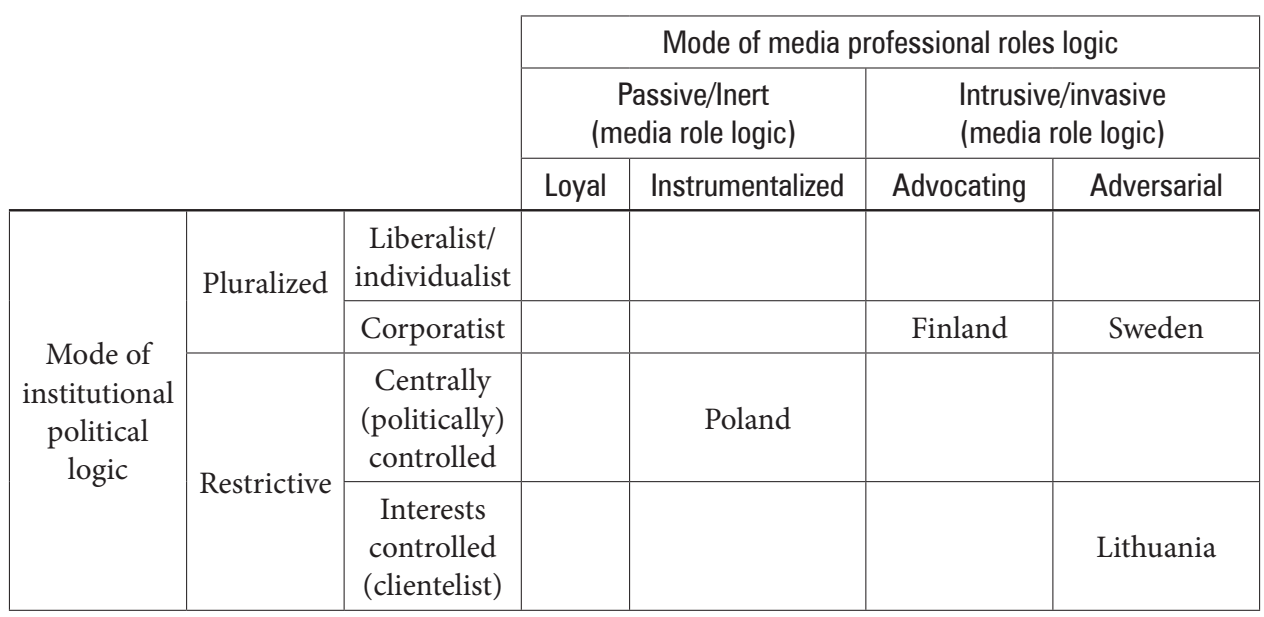

Figure 1. Modes of political institutional logic and media professional roles logic in four countries

Source: Balčytienė \& Moring, 2018, forthcoming.

mental communication is politically controlled. In Sweden corporatist-adversarial intentions and combined logic are identified. Communication culture appears to be media-driven; the autonomy of the media is pronounced in the attitudes among both politicians and journalists (Balčytienė \& Moring, 2018, forthcoming).

\section{RESEARCH QUESTIONS}

This research concerns communication of Swedish and Polish journalists and political sources represented by ministers and press secretaries in Twitter, a platform where political and media elites usually interact. It is focused on the 'everyday routine' examination of a normal working cycle and embraces the following research questions:

- RQ 1. How do Polish and Swedish journalists and their sources (ministers in office and their press secretaries) interact in Twitter?

$-\mathrm{RQ} 2$. What role do press secretaries play in this network?

- RQ 3. Who takes the gatekeeping function in the Polish and Swedish journalist-source Twitter networks?

\section{OLD AND NEW GATEKEEPERS}

One of the most significant topics of journalist-source relations results from issues of power, control, and influence. Thus, the new/old question arises: who is the most powerful, or, in other words, which party "leads the tango" if, for example, exercising power is understood in the terms of three keystone theories as gatekeeping, 
agenda setting, and framing? The answers can vary from state to state and can also be different, depending on other factors as content and the news making process. On the one hand, "the journalists respect their official sources, reporting what these sources tell them" (Gans, 2003, p. 46). On the other hand, journalists mostly "lead the tango": they choose a partner and decide to end the dance or to change a theme (Strömbäck \& Nord, 2006).

Traditionally, media played an intermediary role between politicians and the public. Journalists acted as gatekeepers and decided agenda setting and framing matters. Now the old top-down and one-way form of communication coexists with a more horizontal one. Participants are now free to choose partners, time, place and topic of conversation and can interact with each other directly, bypassing a center or intermediary. It increases interactivity and feedback potential. At the same time, new media reduce the role of journalism to mediate the relationship between citizen and politician that means a trend to disintermediation (McQuail, 2010, pp. 130-131).

This new form of communication organized around the Internet and horizontal digital communication networks is defined by Castells (2011, p. 779) as mass selfcommunication - a self-generated, self-directed, and self-selected model lying between interpersonal and traditional mass communications. Thus, new (social) media, having such a specific nature and being an essential part of the hybrid media system, significantly influences journalist-source relations.

The changes became even more significant in conditions of increasing professionalization of political communication - a multi-dimensional process of:

adaptation to and (...) changes in the political system on the one side and the media system on the other and in the relationships of the two systems. (Papathanassopoulos et al., 2007, p. 10)

This phenomenon is quite complex and can be understood for example, as a creation of more relevant organisational structures and practices helping to use media skilfully, to provide better management in media-politics relations, and to reorganise the communicational system toward centralisation for coordination of publicity in more persuasive way.

Professionalization of political communication is also related to the mediatisation of politics and suggests the growth of a specialism related to communicative technologies (Papathanassopoulos et al., 2007, p. 11). Marland et al. (2016, p. 130) point out the increasing centralisation of government communication in the age of digital media. Thus, in conditions of professionalization of political communication and centralisation of government communication, press officers play an increasingly important role in relations between politicians and the public/journalists.

Journalists recognise increasing control in communication with the office of the Prime Minister, stronger centralisation and bureaucratisation of information policy. Swedish journalists call press staffers "filters", in contacts with government 
and with members of parliament (Hagmanch, 2007) while press officers consider themselves as gatekeepers (Johansson et al., 2018, forthcoming).

In Poland, journalists perceive press secretaries as "shields" politicians use to push away some uncomfortable questions. They hide themselves behind the communication departments and practically speaking, journalists try to avoid contacts with press secretaries and contact politicians directly. Press secretaries "try to disseminate only good news about politicians while journalists segregate that information and try to put it on the appropriate path" (Dobek-Ostrowska \& Nożewski, 2018, forthcoming).

For rethinking the old question about a leading role in the "tango" in journalistsource relations in the new conditions, it would be crucial to define the frameworks of this discussion. What does 'power', 'control' and 'influence' actually mean in terms of new digital media, and ultimately social media networks? What exactly do those actors do to be influential, what do they impact on? How can gatekeeper functions be comparable with the completely different status of communication in social media networks?

Castells defines power "as the relational capacity that enables a social actor to influence asymmetrically the decisions of other social actor(s) in ways that favour the empowered actor's will, interest, and values" (Castells, 2009, p. 10). He introduces four types of power in the network society. The first, networking power, is the power over actors included in the networks; it operates by exclusion/inclusion and "consists of the capacity of letting a medium or a message enter the network through a gatekeeping procedure" (Castells, 2009, p. 418).

The second, network power, is the power of the standards or protocols of the network over its components; communication should fit to these norms.

The network-making power is exercised by programmers and switchers. Programmers "constitute network(s), and program/reprogram the network(s) in terms of the goals assigned to the network". Switchers "connect and ensure the cooperation of different networks by sharing common goals and combining resources, while fending off competition from other networks by setting up strategic cooperation" (Castells, 2009, pp. 45-47).

Finally, networked power embraces dominated and subordinated nodes, agenda-setting, management, decision making, and other editorial processes, and this is what journalist-source relations are associated with (Castells, 2009).

Later Castells (2011) developed and clarified his concept of four different patterns of power in the network society by referring to network gatekeeping theory by Barzilai-Nahon (2008). This theory is distinguished from the classical gatekeeping theory, usually applied to journalists' functions in society. The network gatekeeping theory identifies gatekeepers as actors that have the discretion to exercise gatekeeping through gatekeeping mechanisms in networks and can choose the extent to which it is exercised (Figure 2). Network gatekeeping is a "process of controlling information as it moves through the gate. Activities include, among others, 
selection, addition, withholding, display, channelling, shaping, manipulation, repetition, timing, localisation, integration, disregard, and deletion of information" (Barzilai-Nahon, 2008, p. 1496).

Himelboim et al. (2017) suggest four social network concepts as density, modularity, isolates, and centralization for network analysis. The first three concepts identify users' interconnectedness. The fourth one (centralization) depicts networks from the point of a hierarchy of information flow and shows the degree to which connections are aggregated around just a few actors in the network. It characterizes an extent to which a network structure is hierarchical or egalitarian. If one or a few actors attract a larger number of connections, information flow and sharing in this network depends on these people. These 'key users' are hubs in their networks; they can also be identified as gatekeepers.

Gatekeeping in the networks have certain specificities, and can be described differently. Keegan and Gergle (2010, p. 131) identify "one-side gatekeeping" as an asymmetric process where 'elite' users fulfill a unique gatekeeping role that permits them to leverage their community position to block the promotion of inappropriate items. Coddington and Avery (2014, p. 251) point out that gatekeeping can take a hybrid function: they confirmed that gatekeepers can combine a softer approach grounded in a multilateral relationship with gated users with traditional gatekeeping authority to shape and filter the messages those users were producing. Heinde-

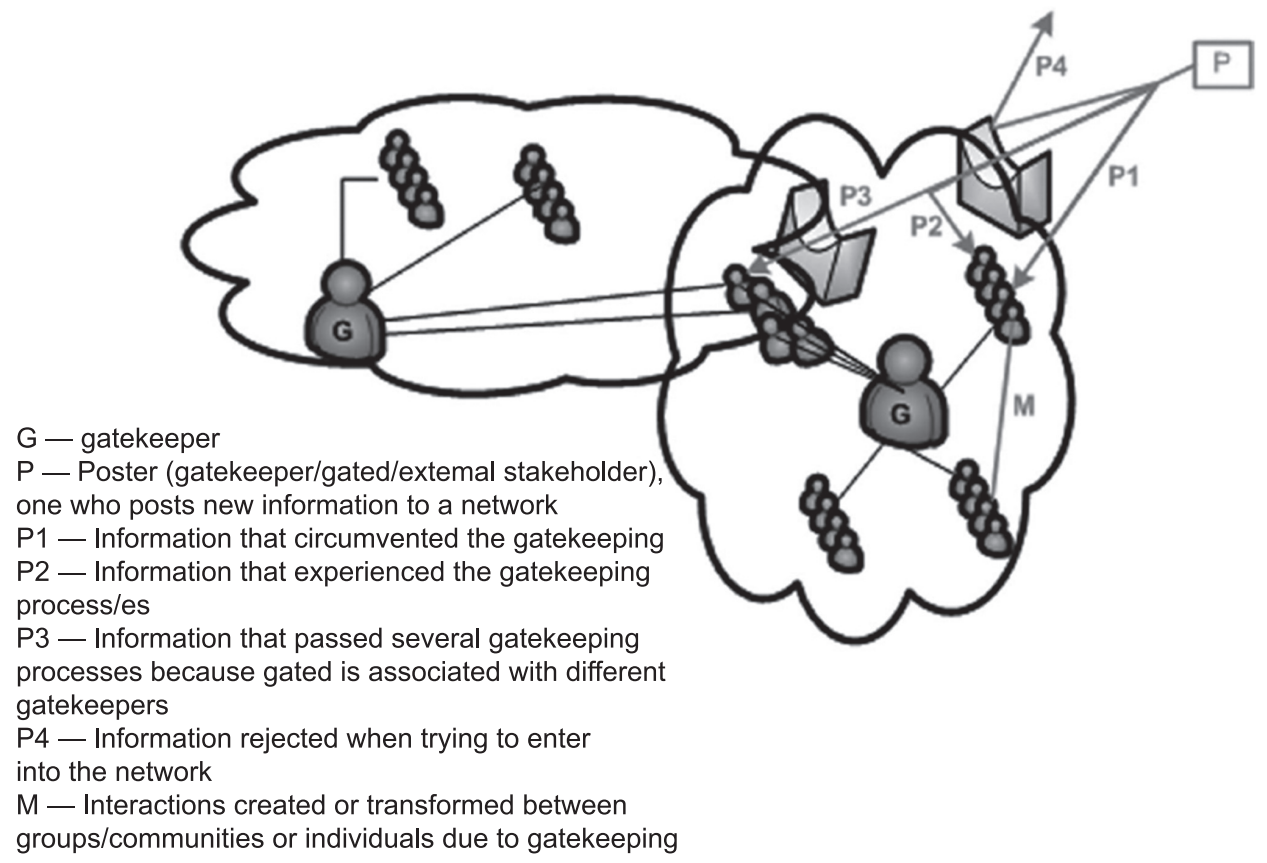

Figure 2. Network gatekeeping

Source: Barzilai-Nahon, 2008. 
ryckx and Vos (2016) argue that gatekeeping in the digital age has shifted towards logic of popularity and gatekeepers act as curators who merely navigate and select information and relay bits that can be easily repurposed. They are more gatewatchers than gatekeepers.

One more important point for understanding communication in social media refers to so-called social media logic. Van Dijck and Poell (2013, p. 5) define it as the processes, principles, and practices through which new media platforms "process information, news, and communication, and more generally, how they channel social traffic". There are four basic elements in the social media logic: popularity, connectivity, datafication, and programmability. The last factor can significantly influence the abilities to provide a network gatekeeping function because it means a process when 'the sites' owners may tweak their platforms' algorithms and interfaces to influence data traffic" (Van Dijck \& Poell, 2013, p. 5).

The link between the activity of Twitter and Facebook users, mainstream media, and offline political events is clear. The majority of the most popular users are politicians and established journalists and bloggers. In 2016, 62 percent of Poles used Facebook and 24 percent Twitter (Statista - The portal for statistics). In Sweden, 71 percent of the population prefer Facebook, 18 percent - Twitter (Svenskarna och internet, 2016). Thus, Facebook is more popular than microblog Twitter in Poland and Sweden. However, Andersson Schwarz et al. (2015, p. 21) mention that Twitter in comparison with Facebook is much more represented as a source in quality Swedish newspapers. Moreover, Twitter (especially in Sweden) obtained a reputation of an 'elitist' social media.

In this regard this platform serves as "a new outlet for speakers already belonging to an elite or at least affiliated with prominent positions in mainstream media or political life in general" (Larsson \& Moe, 2011, p. 741). Johansson (2018, forthcoming) points out that in Poland and Sweden, Facebook serves mostly as a channel for top-down communication with political partisans than for interaction with journalists.

Larsson and Moe (2011) suggest categorization of users related with activity and an ability to produce unique content and to share content produced by others. The first group include: senders - more active high-end users, receivers - users who receive many directed messages but not active in sending messages on their own, sendersreceivers - well-rounded users with regard to exchanging messages with each other.

In the second group, re-tweeters are users actively disseminating the messages of other users; users classified as networkers are distinguished by their tendency to retweet and to be retweeted; 'elite' status is related with popularity in the network and frequency as their messages are retweeted. The authors conclude that most high-end users are politicians and established journalists and bloggers, while Twitter serves "as a new outlet for speakers already belonging to an elite or at least affiliated with prominent positions in mainstream media or political life in general" (Larsson \& Moe, 2013, p. 741). 
Ekman and Widholm (2014, p. 79) introduce a concept of mediatized interdependency, a form of interaction where journalists and politicians in Twitter have become both actors and sources and reliant on each other to get their work done properly. Both sides use microblogging to profile themselves; it is also important for a gaining of public status and upholding of professional prestige. This case study indicates also two main impact factors for using politicians' tweets as news sources for traditional media - negativity and personification. It means that politicians' communication on Twitter contributes to increasingly de-politicizing politics and personalization ('celebritization') in political journalism (Ekman \& Widholm, 2014).

Analyzing Twitter use by Members of the German Bundestag (MdBs) before and during the 2013 election in Germany, Nuernbergk and Conrad (2016, p. 12) found a substantial representation of journalistic actors in politicians' networks. They link these interactions with part of MdB's individual performance of "news management". Thus, political actors episodically use Twitter for intervention in media and by referring to media in order to engage themselves in mediating politics in a 'hybrid' sense.

With regard to politician-journalist relations per se, the role of social media is of special interest. Verweij's case study (2012) should be mentioned here, which examines Twitter links between Dutch politicians and journalists using network analysis. The author concludes that spreading and finding news is the driving force for the journalists-politicians network in Twitter. He also argues that the network connection between stakeholders does not seem as a closed elite or a fully connected group of individuals who take control of information. This network is not closed while journalists and politicians are mutually dependent on each other. Verweij identifies that within a 'professional network sub-groups' are closely connected and serve as an important milieu to do their work.

\section{SAMPLE AND METHOD}

\section{Sample}

For this research three groups of representatives have been sampled: Polish and Swedish ministers-in-office, their press secretaries, and political journalists representing the most influential media. Twitter networks have been chosen for the analysis because journalists and political sources are weakly interconnected in Facebook, the communicative potential of Facebook networks is poor and not a matter of network analysis (Johansson, 2018, forthcoming). Moreover, politicians usually prefer to restrict public access to their personal profiles in Facebook, which makes it difficult to gather data for analysis. Conversely, Twitter is identified as a venue for political and media elites and this platform is open by default: access to personal profiles cannot be restricted. Thus, the following representatives who have Twitter profiles have been selected: 14 ministers, 10 press secretaries, and 31 journalists in the Polish case and 22, 37, and 32 actors accordingly in the Swedish one. 


\section{Method}

The methodological approach is based on social network analysis provided by Gephi - software for providing statistical data and visualization of networks. This method demonstrates how actors related with each other and how they communicate in the network. Actors in the network analysis are labeled as nodes and vertices. Connections between them are represented by links, ties, and edges. Usually social networks are composed of connections that can be reciprocal or not. In Twitter, it can be one-directed and take the form of in-degree (if somebody follows you) and out-degree (if you follow somebody). The type of connection can define a direction of informational flow. Connection in Twitter is exercised by sharing different types of content. Users compose networks by mentioning and replying to one another.

\section{FINDINGS}

\section{Network density: how effectively are actors interconnected?}

Journalists and their sources in Twitter form the apparent networks in both the Polish and Swedish cases. The Polish network, however, is not as plentiful as the Swedish one: Polish ministers and their press secretaries are not so friendly to microblogging. The density coefficient, however, does not depend on the number of actors in the network. This is a measure of interconnectedness effectivity: how many links do actors use from all the possible (potential) connections? A high density coefficient close to 1 means that all the actors (nodes) are well-connected to each other. On the contrary, a density coefficient close to 0 represents networks where we cannot find many connections between users (nodes).

Network density is a measure of interconnectedness of the actors and calculates by the following formula:

$$
\Delta=\frac{E}{n(n-1) / 2}
$$

Here $\mathrm{E}$ is the number of edges in the network and $\mathrm{n}$ is the number of nodes in the network. Density of a graph is the average proportion of edges/lines incident with nodes in the graph. Potential connections $(P c)$ in the networks can be calculated in this way:

$$
P C=\frac{n *(n-1)}{2}
$$

(Wasserman \& Faust, 2009, pp. 100-102)

Density of the Swedish Twitter network is relatively higher (0.80) than the Polish one (0.68). It means that the Swedish network is more compact: actors form more possible (potential) links between each other. Links in the network can, however, take in-degree and out-degree forms. In other words, actors can be followed (in-degree) or following other actors (out-degree). This is related with their func- 
tions as senders and receivers of information in the network in terms of Larsson and Moe (2011).

Estimation of in-degree and out-degree links in Twitter networks exposes that all the groups of actors are almost equally involved in informational exchange. However, according to network analysis data, journalists are following and followed by others almost in the same proportion: they are senders-receivers (see Figure 3). Ministers have fewer out-degree links: they are mostly followed than following and serve rather as sources of information (senders). Press secretaries demonstrate the opposite picture: they are rather following than followed (receivers). It means that information flows in the networks are mostly directed from journalists and from ministers in both cases. Press secretaries have more gates for ingoing information.

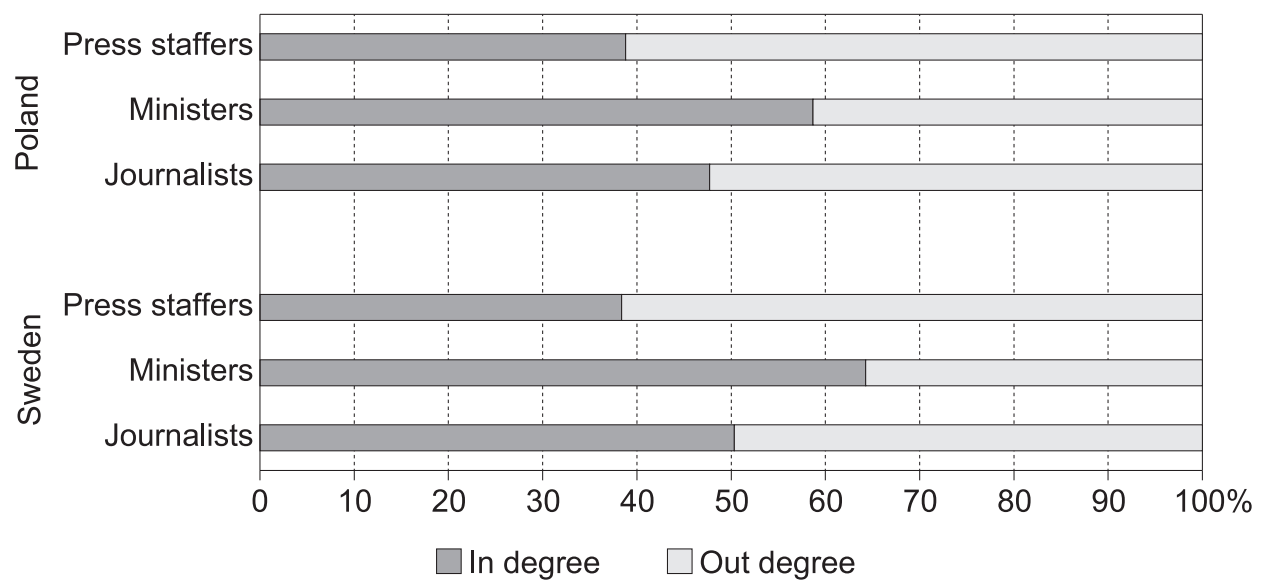

Figure 3. In-degree and out-degree links in Twitter networks (in percent)

Note: Ministers are rather senders of information (mostly followed); press secretaries are rather receivers (mostly following) and journalists are senders-receivers.

Source: Authors.

\section{Clusters and modularity: groups formed by like-minded users}

In Twitter, communities or clusters are created when actors follow one another. They create pathways for the flow of information when they create these connections. These groups are usually formed by like-minded users ("birds of a feather flock together") and define the "social boundaries of information flow" (Himelboim et al., 2017, p. 3). Within these clusters, information flows freely but it is restricted by the limited connectivity across clusters. Thus, modularity class demonstrates how actors (nodes) form particular modules (groups or communities usually formed by like-minded users who follow each other and create pathways for informational flows) in the network. Modularity class is a measure which allows us to check how many communities appear in the analyzed network. 
In the Polish case, we can see three communities or modules (Figure 4). All the modules are more or less mixed, but with predominance of some professional groups. Thus, Polish journalists in the Module 3P, take 84 percent. Module 1P is the 'ministers' community'; it counts more than 50 percent of ministers. In the 'journalists' community (3P), actors are better interconnected: density coefficient is 0.70 . In the 'ministers' module $(1 \mathrm{P})$, this value is 0.63 .

Module $2 \mathrm{P}$ represents press secretaries, journalists, and ministers who are mixed more evenly and highly interconnected: density coefficient is 0.74 . The communication structure between all the actors is relatively equal for all. There is not any balanced component which connects press secretaries and journalists in the Polish case. The majority of press secretaries are closer to the 'ministers' community than to the 'journalists' one.

In the Swedish network, there are three main communities, also mixed. Module $3 \mathrm{~S}$ consists of ministers and press secretaries, Module $1 \mathrm{~S}$ represents mostly journalists (about 60 percent), and two equal parts of other actors, Module $2 S$ includes mostly press secretaries ( 47 percent) and journalists ( 40 percent). Actors in module $3 \mathrm{~S}$ (ministers and press secretaries) are organized and interconnected best of all: density coefficient is 0.87 . In the other two modules, this value is slightly lower: density 0.73 for module $2 \mathrm{~S}$ ('journalists and press secretaries') and 0.71 for module $1 \mathrm{~S}$ ('journalists').

\section{Clustering coefficient: which structure conveys information more quickly?}

Clustering coefficient is a measure of the fraction of possible interconnections between the neighbors of particular nodes (actors). In other words, it shows a structure of the network, or in some way how particular nodes tend to connect to one another. It can take two forms: more hierarchal (so-called star-shape mode) if the value close to 1 and more egalitarian (clique-shape mode) if the value is close to 0 . If a particular actor has many connections with other well interconnected actors, it can create some kind of clique-shaped network - a compact and dynamic communication space. Thus, information can be conveyed and shared more quickly in the network with low clustering coefficient (a tendency for a clique-shape mode). The mode of the structure (star-shaped or clique-shaped) does not correlate directly with the number of followers.

Clustering coefficient of a node $(C C(v))$ is equal to the number of links between neighbors of a particular node $(N v)$ divided by particular node degree $(K v)$ :

$$
C C(v)=\frac{2 N v}{K v(K v-1)}
$$

(Bruggeman, 2008, pp. 22-23)

For the Swedish network at whole, the average clustering coefficient is 0.61 ; it rather tends to be a clique-shape mode. Thus, the communication structure here is 
Sweden

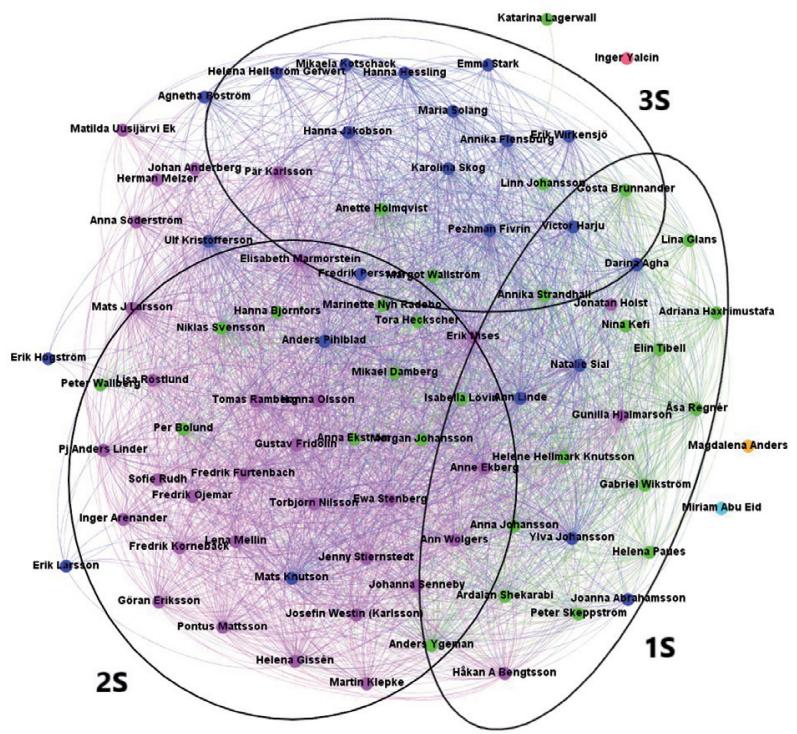

Poland

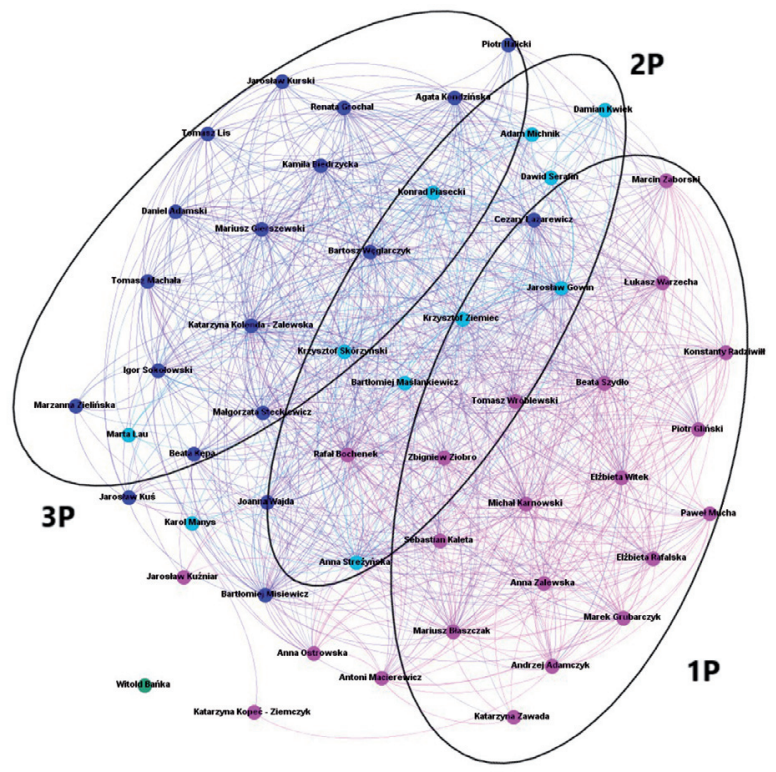

Figure 4. Modularity class

Notes:

Swedish network: Module 1S - mostly journalists; Module 2S - journalists and press secretaries; Module $3 \mathrm{~S}-$ ministers and press secretaries

Polish network: Module 1P — mostly ministers; Module 2P — mixed; Module 3P — mostly journalists

Source: Authors. 
more comprehensive, and consists of many actors who are involved in the information flow. In the Polish case, this value is lower: 0.51; it takes neither a star-shaped mode nor clique-shaped one. It can mean that related communication processes tend to be more shredded between all the actors in the Polish case in comparison with the Swedish one.

We can also consider two types of individual actors a.) with a clustering coefficient higher than 0.5 (the darker nodes in Figure 5) and b.) with a clustering coefficient lower than 0.5 (the lighter nodes). There are mostly press secretaries and some journalists whose nodes have the highest clustering coefficient in both networks: Katarzyna Zawada (Ps) - 0.76, Karol Manys (Ps) - 0.67, Damian Kwiek (J) - 0.67, Piotr Halicki (J) - 0.65, Bartłomiej Maślankiewicz (J) - 0.64, Konstanty Radziwiłł (M) -0.63 , and Anna Ostrowska (Ps) -0.62 in the Polish case and Erik Larson (J) - 1.0, Tora Heckscher (Ps) -0.88 , Nina Kefi (Ps) -0.86 , Peter Wallberg (J) - 0.85, Sofie Rudh (Ps) - 0.82, Johan Anderberg (J) - 0.78, and Joanna Abrahamsson (Ps) -0.78 in the Swedish case. They more likely establish clique-shaped structures and provide good 'transmitting' of information between the neighbor nodes (actors).

Actors with the lowest clustering coefficient maintain less dynamic communication areas. For the Polish case, they are firstly ministers: Beata Szydło $(\mathrm{M})-0.40$, Anna Streżyńska (M) - 041 and journalist Katarzyna Kolenda-Zalewska (J) 0.41. In the Swedish network three journalists, Niklas Svensson (J) and Anette Holmqvist (J) have the lowest clustering coefficient ( 0.46 for both) and Ulf Kristofferson $(\mathrm{J})-0.47$. The lowest clustering coefficient of all the actors is probably related to a relatively central position they possess in the whole network. They have too many connections with different actors who are not necessarily connected with each other.

Closeness centrality: who are in the center and who are on the periphery in the network?

The closeness centrality value presents proximity of entities in comparison to the whole network. In other words, it depicts how particular entities (actors) can distribute information through the network. The lower result of closeness centrality (lighter and smaller nodes) means that they possess the higher possibility to establish contacts with others and are better positioned to disseminate information through the network (Figure 6). Nodes accumulated in the middle of the network probably possess the shortest paths to communicate with the rest of the network. Thus, we can distinguish two types of actors: a) who operate on the periphery and b) who are in the center of the 'communication highway'.

The closeness centrality $\mathrm{C}^{\prime} \mathrm{c}(\mathrm{i})$ is equal to the sum of the distances (geodesics) divided by number of all nodes $\mathrm{N}$ minus one. Here $(\mathrm{Ni})$ is a node, $\mathrm{d}(\mathrm{i}, \mathrm{j})$ is a distance function (the number of lines in the geodesic linking actors $i$ and $j$ ): 


$$
\begin{aligned}
C_{C}^{\prime}(i) & =\left(C_{C}(i)\right) /(N-1) \\
C_{c}(i) & =\left[\sum_{j=1}^{N} d(i, j)\right]^{-1}
\end{aligned}
$$

(Wasserman \& Faust, 2009, pp. 184-186)

The Polish network on the whole is slightly less balanced than the Swedish one. Its density is lower; thus, the actors are generally less interconnected. We can clearly see a center and a periphery in the Polish network. In the center are: ministers Anna Streżyńska -1.33 , Beata Szydło - 1.42; prime minister’s press secretary Rafał Bochenek - 1.33, and some journalists such as Małgorzata Steckiewicz 1.25, Katarzyna Kolenda-Zalewska - 1.40, Krzysztof Ziemiec - 1.40. These actors also have the lowest closeness centrality coefficient. Thus, they have better opportunities to be 'updated' and better abilities to establish contacts.

As mentioned above, the Swedish network is more balanced than the Polish one and has higher interconnectedness between the actors because of the higher density coefficient. There is no any clear center in the network and there are only several actors who have relatively 'peripheral' status. The lowest values of closeness centrality belong to journalists: Anette Holmqvist - 1.09, Elisabeth Marmorstein - 1.11, and Niklas Svensson - 1.17. Other actors with the lowest value are press secretaries: Anne Ekberg (1.20) and Natalie Sial (1.24). Their positions allow them to possess the majority of shortest paths to other actors and provides better chances to be involved in informational exchanges.

Betweenness centrality: who are the 'key users'?

The betweenness centrality concept facilitates the considerations about the probability that communication links (or paths) from one actor to another take a particular route. It means a quantity of paths or avenues which actually pass through the particular node (actor). Figure 7 demonstrates this measure for both networks. Bigger and darker nodes mean the higher value of betweenness centrality: the possibility to pass through these nodes in the network is higher. In other words, if someone needs some information about something or wants to have information about a statement in relation to some issue, it is very possible that the majority of searchers will firstly look at those people profiles. Those actors Himelboim et al. (2017, p. 4) identify as 'key users' or gatekeepers.

The betweenness centrality $(C B(i))$ is equal to the sum of all shortest paths (geodesics, $g$ jk) passes through chosen nodes divided on all shortest paths (geodesics) connected particular nodes:

$$
C_{B}(i)=\sum_{j<k} g_{j k}(i) / g_{j k}
$$

(Wasserman \& Faust, 2009, pp. 189-191) 
Sweden

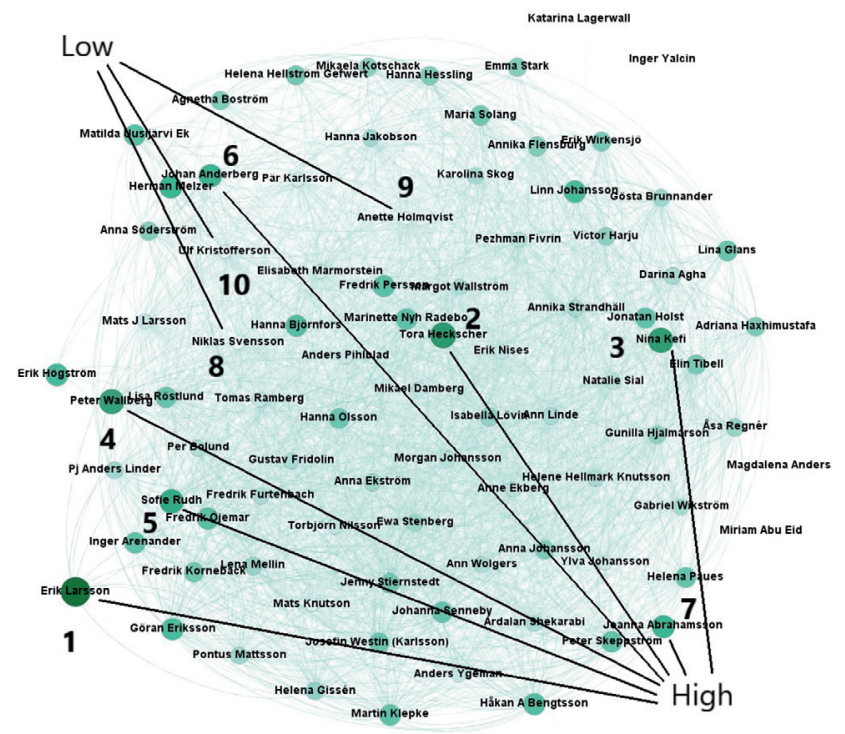

Poland

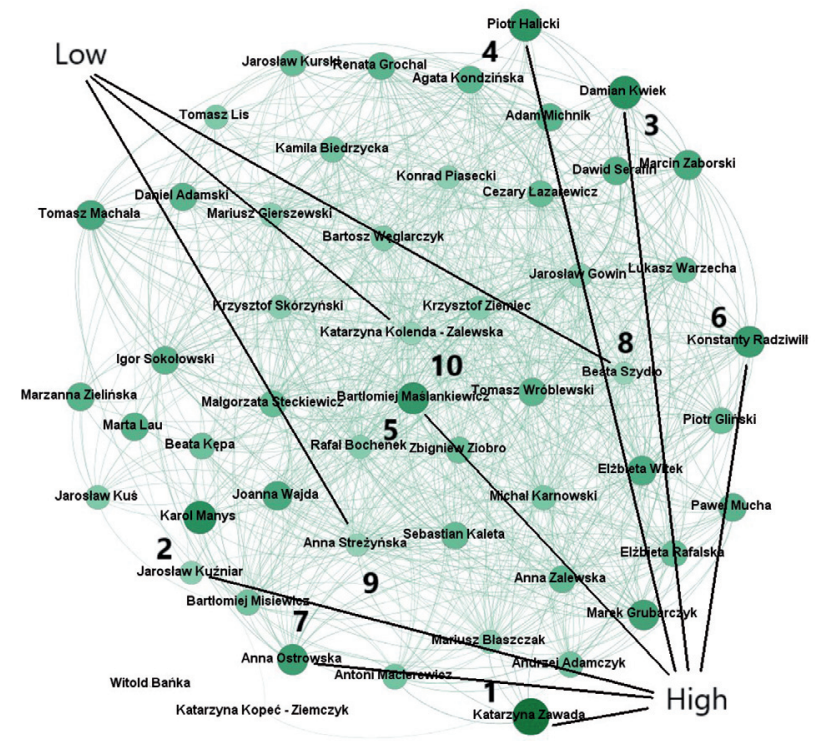

Figure 5. Clustering coefficient

Notes: Swedish network: 1. Erik Larson (J); 2. Tora Heckscher (PS); 3. Nina Kefi (PS); 4. Peter Wallberg (J); 5. Sofie Rudh (PS); 6. Johan Anderberg (J); 7. Joanna Abrahamsson (PS); 8. Niklas Svensson (J); 9. Anette Holmqvist (J); 10. Ulf Kristofferson (J). Polish network: 1. Katarzyna Zawada (PS); 2. Karol Manys (PS); 3. Damian Kwiek (J); 4. Piotr Halicki (J); 5. Bartłomiej Maślankiewicz (J); 6. Konstanty Radziwiłł (M); 7. Anna Ostrowska (PS); 8. Beata Szydło (M); 9. Anna Streżyńska (M); 10. Katarzyna Kolenda-Zalewska (J).

Source: Authors. 
Sweden

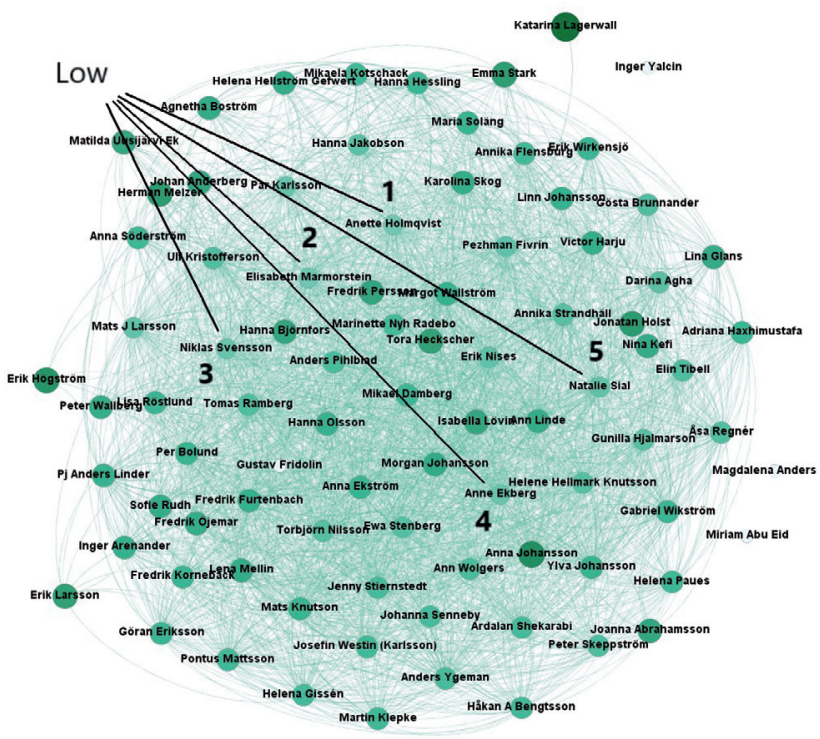

Poland

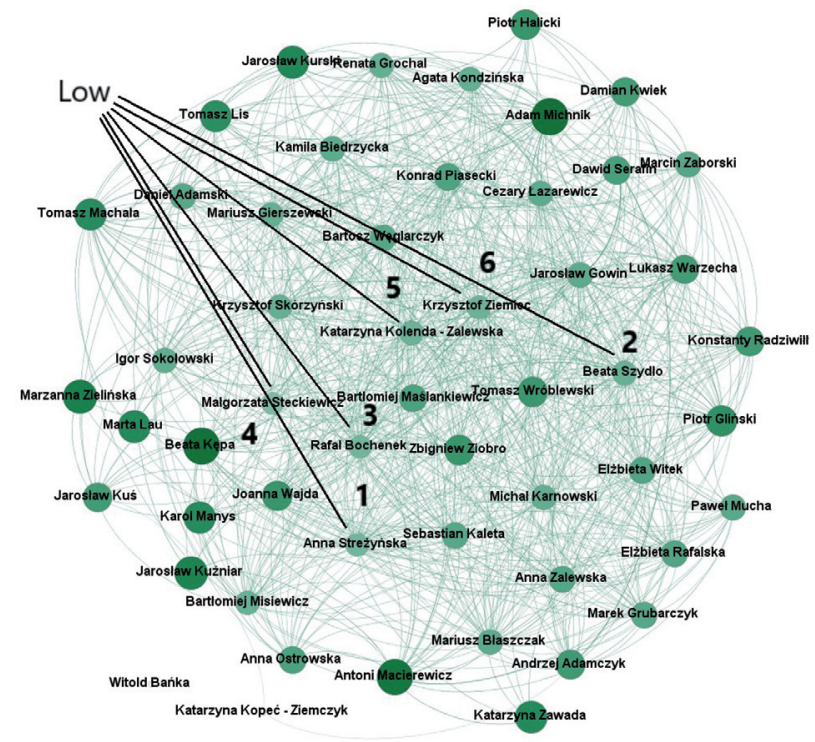

Figure 6. Closeness centrality

Notes: Swedish network: 1. Anette Holmqvist (J); 2. Elisabeth Marmorstein (J); 3. Niklas Svensson (J); 4. Anne Ekberg (PS); 5. Natalie Sial (PS). Polish network: 1. Anna Streżyńska (M); 2. Beata Szydło (M); 3. Rafał Bochenek (PS); 4. Małgorzata Steckiewicz (J); 5. Katarzyna Kolenda-Zalewska (J); 6. Krzysztof Ziemiec (J).

Source: Authors. 
In the Polish case, ministers Anna Streżyńska - 143.86, Beata Szydło - 143.05, and the prime-minister's press secretary Rafał Bochenek - 173.88, possess the highest level of betweenness centrality in the network. There are also some journalists who facilitate the probable information exchange: Katarzyna Kolenda-Zalewska - 101.32, Krzysztof Ziemiec - 127.06, Krzysztof Skórzyński - 92.32, but their coefficient of betweenness centrality is generally lower than their political sources. Thus, it would be correct to say that the gatekeeping function in the Polish network is rather associated with the political side.

The Swedish network has more nodes and edges; the actors have more possibilities to follow each other than in the Polish one. Values of betweenness centrality in the Swedish network are generally higher than in the Polish one. There are significantly more passes through particular nodes in comparison to the Polish network. There are two main nodes the main communication flows can pass through and they belong to the journalists: Niklas Svensson - 360.49, and Annette Holmqvist - 325.65. The other three bigger nodes also represent the 'journalistic' side: Elisabeth Marmorstein - 233.14, Pär Karlsson - 153.58, and Hanna Jakobsson - 146.65. They can be identified as 'key users' or gatekeepers in the network. Betweenness centrality coefficients are much lower for political sources: ministers Annika Strandhäll - 141.81, Margot Wallström - 109.53, and press secretaries Erik Nises - 123.15, Natalie Sial - 109. 99, and Anne Ekberg - 109.06.

\section{CONCLUSIONS AND DISCUSSION}

The presented findings indicate the different states of Polish and Swedish journalistpolitical sources networks in Twitter and different communicative patterns of actors. Microblogging is not equally used in the two chosen countries; Swedish ministers and press secretaries are significantly friendlier to this service than Polish ones. Moreover, Swedish stakeholders are generally better interconnected in the network; there are more ties between them, and consequently more opportunities to follow each other and to spread information through the Twitter platform. Informational flows in both networks are directed from journalists and from ministers.

Both networks have clear communities - modules, usually mixed. Swedish press secretaries form two separated communities with ministers and with journalists. It could reveal apparent 'cooperation' between journalists and press secretaries and could also be a sign of higher professionalization of Swedish political communication. Polish press secretaries don't establish any special community with journalists; they are much closer to ministers. Thus, it appears that journalists try to bypass them and prefer to follow politicians directly on Twitter. They can serve rather as a leverage for information exchange than as individual sources of information for journalists. However, the Polish prime minister's press secretary is an exception.

In general, Swedish actors to a greater extent tend to establish communication cliques than Polish ones. They more likely maintain the communication space 
Sweden

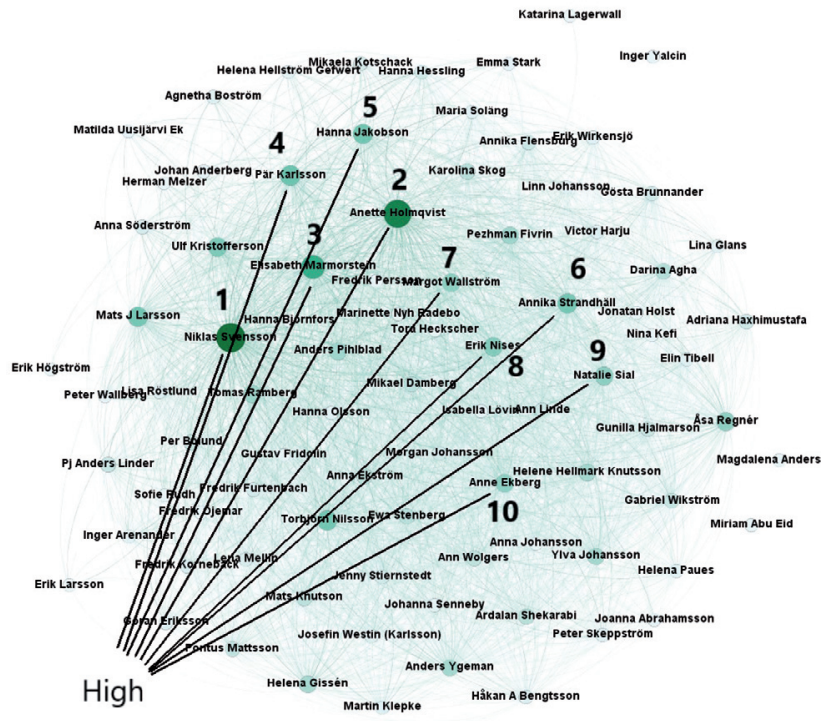

Poland

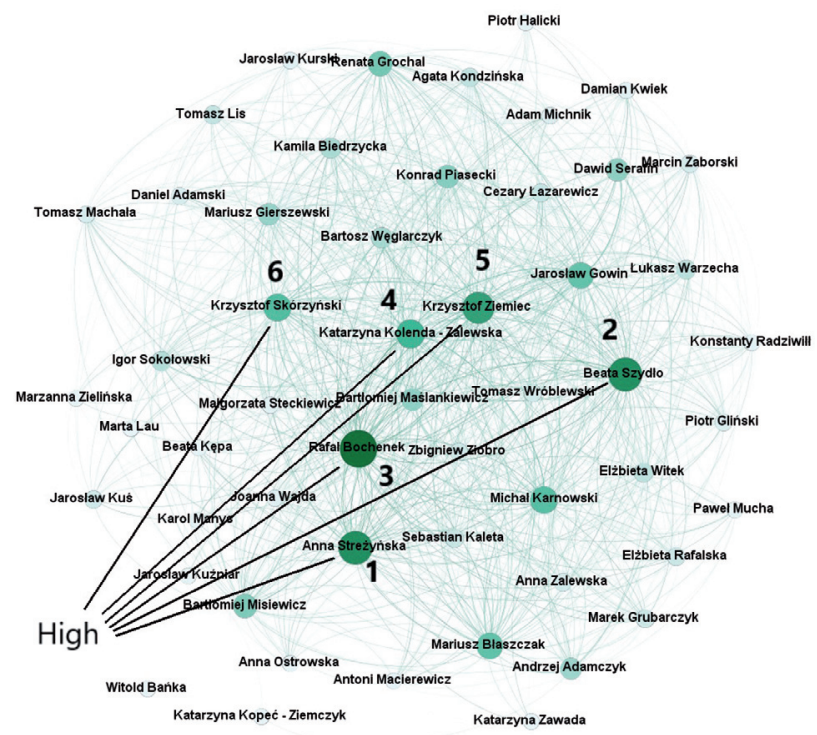

Figure 7. Betweenness centrality

Notes: Swedish network: 1. Niklas Svensson (J); 2. Annette Holmqvist (J); 3. Elisabeth Marmorstein (J); 4. Par Karlsson (J); 5. Hanna Jakobsson (J); 6. Annika Strandhäll (M); 7. Margot Wallström (M); 8. Erik Nises (PS); 9. Natalie Sial (PS); 10. Anne Ekberg (PS). Polish network: 1. Anna Streżyńska (M); 2. Beata Szydło (M); 3. Rafał Bochenek (PS); 4. Katarzyna Kolenda-Zalewska (J); 5. Krzysztof Ziemiec (J); 6. Krzysztof Skórzyński (J).

Source: Authors. 
which more effectively transmits information by tweeting, retweeting, and replying. Polish actors generally operate in a more open environment. Looking at individuals, in both networks mostly journalists and press-secretaries establish compact clique-shaped structures, which provide quick transmitting of information between the neighbor nodes (actors). Hierarchical star-shape structures, which better convey information from individuals to other users, form mostly journalists in the Swedish case and ministers in the Polish one.

We can also identify top users, who are more influential in terms of taking a position closer to the network center or to the periphery. Centralization does matter when it comes to reciprocal communication. In this sense, we can distinguish: 1) individuals (influential entities) with high capabilities, spreading the information through the networks and 2) groups (modules) which demonstrate the relations between particular actors and abilities to form a communication structure. The Swedish network is more balanced; in the Polish one there are clear groups of actors who operate in the center and on the periphery.

Actors in the midpoint of 'informational highway' have a greater possibility to establish contacts with others and to spread information. They are journalists in the Swedish case. Mostly ministers and prime minister's press secretary are in the center of the Polish network. However, periphery actors who don't possess capabilities to spread information, have a big chance to be 'heard' here: they are followed by influential and more centralized stakeholders, which is not obvious in the Swedish case. Looking at betweenness centrality, which is related to the gatekeeping position according to Himelboim et al. (2017), we can again conclude that in the Swedish network these 'key users' are journalists, while in the Polish one - their political sources: mostly ministers and state minister's press secretary.

Who are the gatekeepers in Polish and Swedish Twitter networks: journalists or their political sources as ministers and press secretaries? One of the limitations in this research is that network analysis alone does not provide us with a single-valued understanding as a matter of fact. We need at least to conduct a content analysis to reach a more explicit conclusion. Here we can only estimate who has more potential to exert a more influential role in the whole communication or relational structure. In other words, which actors have more 'communicative capability', or 'accumulated communicative resources' in these specific networks?

This estimation is based on their potential capacities to take a certain position in the network, to maintain connections with other actors, to form communities, and, consequently, to spread information effectively and to control information flows. According to this approach we suppose that in the specific Swedish Twitter network, journalists have more opportunities to pretend the role of gatekeepers, (or, at least, 'key users'), while in the Polish one - their political sources. This statement, however, does not mean that the actors "lead the tango" in these Twitter networks, rather that they could potentially "play first fiddle". 
Polish and Swedish journalist-politician Twitter networks: Who are the gatekeepers?

\section{ACKNOWLEDGEMENTS}

This article is the joint product of research conducted within the project "Symbiotic leader-media relations? Exploring interaction between prime ministers and the media in Finland, Lithuania, Poland, and Sweden" (https://www.polexmedia.com/), funded by the Foundation for Baltic and East European Studies (Östersjöstiftelsen). Elena Johansson wishes to thank Jonas Andersson Schwarz for sharing his time and insights, and Tapio Raunio for inspiring discussions.

\section{REFERENCES}

Andersson-Schwarz, J., Hammarlund, J., Grado, S., \& Kjellberg, M. (2015). Opinioner och offentligheter online. Vad gör en politisk utsaga framgångsrik? Den användardrivna kommunikationens villkor. Slutrapport [Opinions and publicity online. What makes a political statement successful? Conditions of user-driven communication. Final report]. Internetfonden. Stockholm, November 2015.

Balčytienè, A., \& Moring, T. (2018, forthcoming). Political communication cultures in four countries. In: K. M. Johansson \& G. Nygren (eds.), Close and Distant: Political Executive - Media Relations in Four Countries. Göteborg: Nordicom.

Barzilai-Nahon, K. (2008). Toward a theory of network gatekeeping: A framework for exploring information control. Journal of the American Society for Information Science and Technology, 59(9), pp. 1493-1512.

Berkowitz D. A. (2009). Reporters and their sources. In: K. Wahl-Jorgensen \& T. Hanitzsch (eds.), The Handbook of Journalism Studies. New York: Routledge.

Bruggeman, J. (2008). Social Networks. An Introduction. New York: Routledge.

Castells, M. (2009). Communication Power. Oxford: Oxford University Press.

Castells, M. (2011). A network theory of power. International Journal of Communication, 5, pp. 773-787.

Chadwick, A. (2013). The Hybrid Media System: Politics and Power. Oxford: Oxford University Press.

Coddington, M., \& Holton, A. E. (2014). When the gates swing open: Examining network gatekeeping in a social media setting. Mass Communication and Society, 17(2), pp. 236-257.

Dobek-Ostrowska, B. (2012). Italianization (or mediterraneaization) of the Polish media system? reality and perspective. In: D. C. Hallin \& P. Mancini (eds.), Comparing Media Systems beyond the Western World. Cambridge: Cambridge University Press, pp. 26-50.

Dobek-Ostrowska, B. (2015). Journalism and politics. In: G. Nygren \& B. Dobek-Ostrowska (eds.), Journalism in Change - Professional Journalistic Cultures in Poland, Russia and Sweden. Frankfurt am Main: Peter Lang Edition, pp. 179-210.

Dobek-Ostrowska, B., \& Nożewski, J. (2018, forthcoming). Poland - independent vs. servile relations. In: K. M. Johansson \& G. Nygren (eds.), Close and Distant: Political Executive - Media Relations in Four Countries. Göteborg: Nordicom.

Ekman, M., \& Widholm, A. (2014). Politicians as media producers. Journalism Practice, Vol. 9(1), pp. 78-91.

Falkheimer, J. (2005). Formation of a region: Source strategies and media images of the SwedenDanish Öresund region. Public Relations Review, 31, pp. 293-295.

Gans, H. J. (2003). Democracy and the News. New York: Oxford University Press.

Głowacki, M. (2008). Political pressure on public television in Poland. The case of national broadcasting council. In: B. Dobek-Ostrowska \& M. Głowacki (eds.), Comparing Media Systems in Central Europe. Wrocław: Wydawnictwo Uniwersytetu Wrocławskiego, pp. 111-121. 
Hagmanch, C. (2007). Journalister oroas över pressekreterares insyn [Journalists concerned about press secretaries' scrutiny]. Journalisten. 27.02.2007. Retreived on 10 May, 2018 from https:// www.journalisten.se/nyheter/journalister-oroas-over-pressekreterares-insyn.

Hallin, D. C., \& Mancini, P. (2004). Comparing Media Systems. Three Models of Media and Politics. Cambridge: Cambridge University Press.

Hallin, D. C., \& Mancini, P. (2017). Ten years after comparing media systems: What have we learned?. Political Communication, Vol. 34, Issue 2, pp. 155-171.

Heinderyckx, F., \& Vos, P. T. (2016). Reformed gatekeeping. Communication and Media, XI (36), pp. 29-46.

Himelboim, I., Smith, M. A., Rainie, L., Shneiderman, B., \& Espina, C. (2017). Classifying Twitter topic-networks using social media analysis. Social Media + Society, Vol. 1-13, pp. 1-13.

Johansson, E. (2018, forthcoming). Social media for top politicians: Comparative case illustrations from Finland, Poland and Sweden. In: K. M. Johansson \& G. Nygren (eds.), Close and Distant: Political Executive - Media Relations in Four Countries. Göteborg: Nordicom.

Johansson, K. M., Malling, M., \& Nygren, G. (2018, forthcoming). Sweden — a professionally symbiotic relationship. In: K. M. Johansson and G. Nygren (eds.), Close and Distant: Political Executive - Media Relations in Four Countries. Göteborg: Nordicom.

Keegan, B., \& Gergle, D. (2010). Egalitarians at the Gate: One-Sided Gatekeeping Practices in Social Media. Paper presented at the 2010 ACM Conference on Computer Supported Cooperative Work, CSCW 2010, pp. 131-134.

Larsson, A. O., \& Moe, H. (2011). Studying political micro-blogging: Twitter users in the 2010 Swedish election campaign. New Media and Society, 14(5), pp. 729-747.

Marland, A., Lewis, J. P., \& Flanagan, T. (2016). Governance in the age of digital media and branding. Governance. An International Journal of Policy, Administration and Institutions, 30(1), pp. 125-141.

McQuail, D. (2010). McQuail's Mass Communication Theory. $6^{\text {th }}$ edition. Los Angeles: Sage.

Nuernbergk, Ch., \& Conrad, J. (2016). Conversations and campaign dynamics in a hybrid media environment: Use of Twitter by members of the German Bundestag. Social Media + Society, Vol. January-March, pp. 1-14.

Papathanassopoulos, S., Negrine, R., Mancini, P., \& Holtz-Bacha, Ch. (2007). Political communication in the era of professionalisation. In: R. Negrine, Ch. Holtz-Bacha, P. Mancini, \& S. Papatha (eds.), The Professionalisation of Political Communication. Chicago: Intellect Books, pp. 9-25.

Strömbäck, J., \& Nord, L. (2006). Do politicians lead the tango? A study of the relationship between Swedish journalists and their political sources in the context of election campaigns. European Journal of Communication, Vol. 21(2), pp. 147-164.

Van Dijck, J., \& Poell, T. (2013). Understanding social media logic. Media and Communication, 1(1), pp. 2-14.

Verweij, P. (2012). Twitter links between politicians and journalists. Journalism practice, Vol. 6(5-6), pp. 680-691.

Wasserman, S., \& Faust, K. (2009). Social Network Analysis. Methods and Applications. Cambridge: Cambridge University Press.

\section{Internet sources}

Svenskarna och internet 2016. Retrieved on 10 September, 2017 from https://www.iis.se/docs/ Svenskarna_och_internet_2016.pdf.

Statista - The portal for statistics. Retrieved on 10 September, 2017 from https://www.statista.com/ statistics/284441/poland-social-network-penetration/. 